\title{
AUTONOMIA, JUSTIÇA E DEMOCRACIA
}

\author{
CONTEXTOS DA JUSTIÇA: FILOSOFIA POLÍTICA PARA ALÉM DE LIBERALISMO E COMUNITARISMO. \\ de Rainer Forst. Trad. Denilson Luis Werle. São Paulo: Boitempo, 2010.384 pp.
}

RÚRION MELO

[1] Cf. Nobre, M. "Teoria crítica hoje". In: Keinert, M. e outros (orgs.). Tensões e passagens: filosofia crítica e modernidade. São Paulo: Singular/ Esfera Pública, 2008, pp. 265-83.

[2] Avritzer, L. "Teoria crítica e teoria democrática". Novos Estudos Cebrap, $\mathrm{n}^{\circ} 53,1999$, pp.167-188.

[3] Benhabib, S. Critique, norm, and utopia: a study of the foundations of critical theory. Nova York: Columbia University Press, 1986, p. 347.

[4] Arato,A.e Cohen,J. "Politics and the reconstruction of the concept of civil society". In: Honneth, A. e outros (orgs.).Zwischenbetrachtungen:Im Prozess der Aufklärung. Frankfurt/M: Suhrkamp, 1989, p. 493.

[5] Cf. Honneth, A. "Teoria crítica". In: Giddens, A. e Turner, J. (orgs.). Teoria social hoje. São Paulo: Editora da Unesp, 1999, pp. 503-52. Ver também Nobre, M.Ateoria crítica. Rio de Janeiro: Jorge Zahar, 2004.

[6] Benhabib, op.cit., p. ix. Ver também Baynes, K. The normative grounds of social criticism: Kant, Rawls, Habermas. Nova York:Albany, 1991.

[7] Bohman, J. Public deliberation: pluralism, complexity, and democracy. Massachussetts: MIT, 1996, p. 20.

[8] Wellmer, A. "Bedeutet das Ende des 'realen Sozialismus' auch das Ende des Marxschen Humanismus?". In: Endspiele: Die unversöhnliche Moderne. Frankfurt/M: Suhrkamp, 1993, p. 91.
Um dos traços mais característicos da "renovação" da teoria crítica hoje é o enfrentamento dessa tradição de pensamento com o problema da legitimidade e da dimensão normativa das instituições políticas ${ }^{1}$. Cada vez menos os temas considerados pelas teorias críticas da sociedade permitem que se conclua pela "impossibilidade da democracia" ${ }^{2}$, levando antes à formulação de novos diagnósticos vinculados a uma concepção de crítica social mais radicalmente política e pluralista. Quando Seyla Benhabib alerta que "a negligência quanto a uma tal teoria política e democrática é um dos principais pontos cegos da teoria crítica da Escola de Frankfurt"3 e Jean Cohen e Andrew Arato chamam atenção insistentemente para o fato de que "a teoria crítica não pode mais manter seus propósitos práticos sem uma teoria política", uma vez que "a crítica da razão funcionalista precisa ser complementada por uma teoria da democracia"4, esses autores sintetizam uma mudança fundamental na relação entre teoria social e filosofia política partilhada por diversos autores explicitamente filiados à tradição de pensamento que, desde Theodor Adorno e Max Horkheimer, se tornou conhecida como teoria crítica da sociedade5. Essa mudança teórica no projeto original esteve orientada, em linhas gerais, à investigação das "bases normativas da teoria crítica" ${ }^{6}$, ao vínculo entre o "potencial radical da democracia" e o "legado da Escola de Frankfurt" 7 à retradução do núcleo crítico-emancipatório no interior da "programática democrática"8.

Para entendermos melhor o que estaria em jogo nessa mudança de projeto teórico, podemos recorrer brevemente à caracterização do que Axel Honneth chamou de "fraqueza teórica" da primeira geração da teoria crítica, ou seja, àquela formulação ligada principalmente aos nomes de Horkheimer e Adorno. Embora ambos tivessem recusado a referência de Marx à categoria do "trabalho" como conceito determi- 
nante da análise crítica da sociedade e da respectiva orientação emancipatória, os principais representantes da primeira geração permaneceram fechados diante de "todas as tentativas de considerar o processo histórico de um ponto de vista outro que não o do desenvolvimento do trabalho social"9. Esse fechamento acabou levando à desconsideração da dimensão da ação social, na qual convicções morais e intuições político-normativas se constituem independentemente, e priorizou, na interpretação dos processos sociais, as funções de expansão e reprodução do trabalho social. Em suma, subsistiria um "reducionismo funcionalista”, já presente em Marx, responsável por restringir a história humana a uma concepção instrumental de ação. A segunda geração começou a questionar decisivamente os déficits teóricos nos fundamentos normativos da primeira teoria crítica, lançando mão, sobretudo, de outro tipo de ação social que pudesse ao menos ser concebido ao lado do trabalho, e assim abrir caminho à análise da integração social e da dimensão normativa da interação social.

Jürgen Habermas foi o autor dessa tradição que primeiro trouxe à consciência teórica o diagnóstico de que "se esgotou a utopia da sociedade do trabalho"1o e pensou explicitamente o projeto futuro da teoria crítica segundo a necessidade de "superar o paradigma produtivista, sem abrir mão das intenções do marxismo ocidental" ${ }^{11}$. Representante mais importante da segunda geração da teoria crítica, Habermas desenvolveu diagnósticos significativos sobre a esfera pública e temas da moral, do direito e da democracia, buscando eliminar o que entendeu ser o déficit nos fundamentos normativos da crítica social. Também Axel Honneth, não obstante procurasse superar vários aspectos da teoria habermasiana, seguiu explicitamente a crítica ao paradigma produtivista, estabelecendo, agora na terceira geração, uma rica articulação entre crítica e filosofia social. Sua teoria do reconhecimento pretende compreender as formas de reivindicação política assim como a natureza específica dos conflitos e das lutas existentes nas sociedades contemporâneas. Uma das preocupações centrais de seu principal livro, Luta por reconhecimento, consistiu em investigar a lógica dos conflitos sociais, insistindo na necessidade de apresentar a dinâmica de tais conflitos a partir de sua gramática moral implícita ${ }^{12}$.

A renovação representada pelas segunda e terceira gerações da teoria crítica implicou, portanto, a inclusão de categorias que permitissem explicar mais adequadamente as novas formas de luta política e de mobilização cultural que ampliaram os sentidos da emancipação e configuraram atualmente os dilemas e os desafios da democracia contemporânea. Abandonaram-se necessariamente as orientações emancipatórias presas ao paradigma produtivista e se estabeleceu um rico diálogo entre a crítica da sociedade e concepções normativas pre-
[9] Honneth, op. cit., p. 517 .

[10] Cf. Habermas, J. “Volkssouveränität als Verfahren”. In: Faktizität und Geltung. Frankfurt/M: Suhrkamp, 1998, p. 602.

[11] Ibidem. "Ein Interview mit der New Left Review". In:Die Neue Unübersichtlichkeit. Frankfurt/M:Suhrkamp, 1985 , p. 217.

[12] Cf. Honneth.A.Luta por reconhecimento: a gramática moral dos conflitos sociais. Trad. Luiz Repa. São Paulo: Editora 34, 2003. 
[13] Cf. Forst, R. Toleranz im Konflikt. Frankfurt/M: Suhrkamp, 2003; Ibidem. "Os limites da tolerância”. Trad. Mauro Soares. Novos Estudos Cebrap, $\mathrm{n}^{\circ}$ 84, 2009, pp. 15-29; Ibidem. Das Recht aufRechtfertigung. Frankfurt/M: Suhrkamp, 2007; Forst e outros (org). Sozialphilosophie und Kritik. Frankfurt/M: Suhrkamp, 2009. Ver também seu programa de pesquisa social desenvolvido ao lado de Klaus Günther, "Innenansichten: Über die Dynamik normativer Konflikte". In: Forschung Frankfurt 2/2009. O subtítulo de seu próximo livro (no prelo) remete a uma junção explícita entre filosofia política e teoria crítica, a saber, "perspectivas de uma teoria crítica da política". Cf. Forst. Kritik der Rechtfertigungsverhältnisse: Perspektiven einer kritischen Theorie der Politik. Frankfurt/M: Suhrkamp (no prelo).

[14] Os limites existentes nessa "virada normativa" não foram desconsiderados mesmo por aqueles que se preocupam com uma renovação da tradição da teoria crítica. Cf. Honneth. "Das Gewebe der Gerechtigkeit. Über die Grenzen des zeitgenössischen Prozeduralismus". In: Das Ich im Wir: Studien zur Anerkennungstheorie. Frankfurt/M: Suhrkamp, 2010, pp. 51-77. ocupadas com questões de justiça política e social, com a dinâmica política de esferas públicas autônomas, com a participação da sociedade civil e com as lutas por reconhecimento (em que estão envolvidos os dilemas criados por diferenças culturais, orientação sexual, gênero, raça etc.), ou seja, âmbitos de conflitos sociais que requerem uma reflexão renovada sobre a moral, a política e o direito.

Essa rápida e esquemática referência à história da teoria crítica tem o intuito de posicionar o livro de Rainer Forst, Contextos da justiça, no interior dessa mesma tradição teórica. Podendo ser considerado membro de uma "quarta geração" da teoria crítica, Forst voltou-se essencialmente para as questões do pensamento político contemporâneo e foi responsável por uma rigorosa reconstrução de um dos mais importantes debates filosóficos da atualidade no campo das teorias normativas. Suas preocupações teóricas giram em torno da articulação entre crítica social e filosofia normativa, da reconstrução dos temas clássicos do pensamento político moderno e do enfrentamento dos dilemas contemporâneos ligados às questões de justiça, tolerância, cidadania e direitos humanos ${ }^{13}$. Esse rico estoque de problemas indica de certo modo que aquele ponto cego denunciado por muitos autores entre a filosofia política e a tradição da teoria crítica vem sendo superado desde a segunda geração ${ }^{14}$. O passo inicial mais significativo de Forst resultou no exaustivo estudo sobre a justiça política e social a partir de uma visão sistemática e crítica do conhecido debate entre liberais e comunitaristas.

Contextos da justiça, que acabada de ser publicado no Brasil em rigorosa tradução de Denilson Luis Werle, procura analisar criticamente as respostas oferecidas à questão da justificação das normas que tornam legítimas relações jurídicas, políticas e sociais no interior de uma comunidade política. Além de contribuir para o esclarecimento dos conceitos fundamentais das teorias da justiça, Forst pretende também superar a oposição consolidada entre liberalismo e comunitarismo, apresentando uma proposta de solução conceitual própria. Seguindo uma rígida oposição entre os dois polos que compõem o debate analisado, os liberais procuraram fundamentar moralmente uma teoria da justiça abstraindo os contextos sociais concretos e priorizando as liberdades individuais em face de concepções substantivas do bem. Os comunitaristas, por sua vez, criticaram essa tese liberal da prioridade do justo perante o bem e enfatizaram o enraizamento da justificação normativa de concepções de justiça em autocompreensões e tradições constitutivas das comunidades políticas, de modo que só poderiam ser considerados justos aqueles princípios que resultam de um determinado contexto comunitário, e somente ali podem pretender validade. Todas as teorias que sublinham a prioridade do justo diante do bem acabam 
se mostrando "indiferentes ao contexto", ao passo que a teoria comunitarista reforça uma posição "obcecada pelo contexto" (p. 11). Forst, indo além dessa oposição, acredita ser necessário formular uma teoria crítica da justiça capaz de justificar o ancoramento dos princípios normativos nos valores, nas práticas e nas instituições da comunidade política, compatibilizando dessa maneira os aspectos universalistas com a reivindicação de validade daqueles princípios para a autocompreensão e instituições sociais específicas.

A solução conceitual de Forst para os dilemas criados no interior do debate sobre a justiça leva em consideração quatro "contextos de problemas teóricos" em que aspectos da justificação normativa oferecidos por liberais ou comunitaristas podem se mostrar mais ou menos adequados. O próprio conteúdo do livro, portanto, divide-se nesses quatro planos conceituais críticos. Primeiramente, abordam-se criticamente a constituição do selfe os pressupostos de uma concepção atomista de pessoa, típicos da formulação liberal; em segundo lugar, Forst critica a neutralidade do direito diante de visões de mundo e concepções sobre a vida boa que caracteriza a tese liberal da prioridade do justo sobre o bem; em seguida, o texto apresenta uma análise crítica da aposta comunitarista na força eticamente integradora da comunidade política; em quarto lugar, por fim, analisa criticamente a teoria moral universalista e seu vínculo a contextos concretos de justificação. Em cada um desses planos se esclarecem as posições antagônicas de justificação da justiça, as quais permaneceriam, numa "perspectiva horizontal", meramente excludentes.

Forst pretende mostrar a possibilidade de "superar" tais oposições tradicionais segundo uma "perspectiva vertical" a partir de sua tese dos "contextos da justiça". Uma teoria crítica da justiça precisa antes considerar as necessidades que podem surgir no contexto de socialização dos indivíduos e serem justificadas publicamente em dimensões ao mesmo tempo diferenciadas e interrelacionadas. Argumentos universalistas, pretensões de neutralidade jurídica e dimensões axiológicas compõem os contextos de reconhecimento e de justificação pública nos âmbitos da moral, do direito, da ética e da política. "Eles formam", comenta Forst,

[...] quatro "contextos" de reconhecimento recíproco - como pessoa ética, pessoa do direito, cidadão( $\tilde{a})$ com plenos direitos, pessoa moral - que correspondem a diferentes modos de justificação normativa de valores e de normas em diferentes "comunidades de justificação". A análise do debate entre teorias deontológico-liberais "que se esquecem dos contextos" e teorias comunitaristas "obcecadas pelo contexto" levou, com isso, a uma diferenciação de quatro contextos normativos nos quais as pessoas estão "situadas" (p.275). 
Desse modo, aquelas clássicas oposições entre "eticidade" e "moralidade", bem e justiça, são vinculadas a processos de justificação da normatividade em que formas de vida culturais e políticas e determinações substantivas da justiça encontram-se atreladas a direitos e procedimentos imparciais. "Portanto", segue o autor, "princípios de justiça são aqueles que são justificados de modo universal e imparcial na medida em que correspondem, de maneira apropriada, aos interesses, necessidades e valores concretos daqueles atingidos por eles" (p. 276). Pretende-se assim evitar uma "cegueira" em face dos contextos, bem como apontar os limites das orientações contextualistas que desconhecem o núcleo universalista das reivindicações por justiça. A harmonização desses diferentes contextos requer uma teoria da justiça que possa reuni-los de um modo mais adequado.

A reconstrução do debate entre liberais e comunitaristas apresentada no livro evita, por conseguinte, a mera defesa de uma ou outra posição, privilegiando avaliá-los como abordagens parciais para o problema da justiça. Para que seja suficientemente abstrata e concreta ao mesmo tempo, uma teoria crítica da justiça assume o vínculo essencial entre pessoas e comunidades e parte do ancoramento dos princípios de justiça a toda comunidade política. A oposição normativa entre universalismo e contextualismo só pode ser superada se trouxermos para o centro da discussão a questão de quais conceitos de pessoa e comunidade estão em jogo. A solução conceitual de Forst complementa criticamente as proposições globais tradicionais ao distinguir quatro conceitos de pessoa (pessoa ética, pessoa de direito, cidadão e pessoa moral) e de comunidade (ética, jurídica, política e moral) que correspondem a quatro contextos normativos diferentes e entrelaçados de modo complexo:

$A$ identidade ética das pessoas é reconhecida e protegida juridicamente numa sociedade e, na verdade, por meio do direito estatuído de modo político autônomo no interior de uma comunidade política de membros com plenos direitos - direito esse que possui um conteúdo moral em seu cerne, que respeita a integridade de pessoas morais (p.276).

O propósito crítico da diferenciação e da articulação dos diversos contextos consiste menos na separação entre o plano ético, jurídico, político e moral, do que na possibilidade de "comprovar a compatibilidade dos direitos individuais com o bem da comunidade, da universalidade política com a diferença ética, do universalismo moral com o contextualismo", permitindo desse modo "evitar oposições falsas" (p.13).

Podemos chegar às diferenciações internas que compõem os contextos aludidos considerando as relações entre pessoa e comu- 
nidade. A teoria liberal tendeu a desvincular o indivíduo de seus contextos de socialização ao priorizar uma concepção abstrata de pessoa como portadora de direitos ou como pessoa moral. As críticas republicanas e comunitaristas mostraram, ao contrário, que toda pessoa se individualiza nas comunidades em que são integradas. Porém, não sabemos ainda a quais comunidades pertencem as pessoas e quais são as normas e os valores que as integram. Se para o liberal a justiça está fundada num conceito abstrato de pessoa de direito - como portadora de direitos subjetivos e como sujeito de direito -, para o defensor do contextualismo toda pessoa está integrada eticamente a uma determinada comunidade de valores. Embora Forst também não acredite ser necessário reduzir um âmbito ao outro, "verticalmente" é possível justapô-los de acordo com contextos de justificação diferentes e igualmente legítimos: enquanto considero a comunidade político-jurídica e sua integração normativa segundo uma concepção política e pública de justiça, compreendo os indivíduos como pessoas que portam direitos; já as comunidades éticas se integram por diferentes tipos de concepções do bem - e não com base na imagem abstrata e universal da pessoa de direito - de modo que a pessoa ética se torna, dessa perspectiva, membro de determinadas comunidades com as quais a identidade do selfestá vinculada. As relações éticas (constituídas por visões de mundo e concepções de bem ) não substituem relações jurídicas (em que se trata de atentar para direitos e deveres que formam a estrutura de relações reguladas juridicamente). Como diz Forst, "uma coisa é reconhecer uma pessoa como igual portador de direitos; outra coisa é reconhecê-la em todas as suas qualidades" (p. 40). O direito igual justifica-se segundo normas e princípios que pretendem ser universalmente válidos sem que recorramos a concepções de bem e valores particulares. Não importa quais concepções éticas e valores estão em jogo, normas jurídicas (bem como normas morais) têm de valer "para todos": no caso do direito, as normas jurídicas valem para todos os parceiros do direito considerados membros de uma comunidade jurídica; normas morais, por sua vez, valem para todas as pessoas morais consideradas membros da comunidade dos seres humanos. A validade de normas éticas, contudo, depende da identificação dos indivíduos com determinados valores que formam suas identidades do ponto de vista de sua história de vida.

Um dos principais conceitos utilizados por Forst nas quatro dimensões como mediação para redefinir os conceitos de pessoa de direito, cidadania ou de uma moral universalista em contextos intersubjetivos diferenciados é o de autonomia. "Segundo esse conceito", afirma Forst, 
[...] as pessoas como agentes são, no sentido prático, seres "autônomos" autodeterminantes quando agem de forma consciente e fundamentada. Como tais são responsáveis por suas ações: podem ser questionadas acerca das razões pelas quais agiram. Como pessoas responsáveis, são aquelas "que se justificam" e esperamos que tenham considerado suas razões para agir, sendo capazes de justificá-las. Nesse sentido, as pessoas autônomas são razoáveis em termos de razão prática: possuem razões para agir que podem ser justificadas para elas mesmas e comunicadas e defendidas diante de outras, de modo que essas razões [...] possam ser compartilhadas (p.305).

Contudo, também uma diferenciação nos "contextos da autonomia" poderá nos mostrar quais questões práticas e quais respostas autônomas podem se apoiar em razões capazes de ser publicamente reconhecidas. A "autonomia ética" está ligada à validade de valores éticos eà autorealização da pessoa; a "autonomia jurídica" é característica de pessoas de direito e é assegurada a todos os destinatários do direito; a "autonomia política" é exercida pelo cidadão considerado autor dos direitos; e a "autonomia moral" é pressuposta nas pessoas como autoras e destinatárias de normas morais. A justificação normativa exercida nos distintos contextos pode validar argumentos e princípios de justiça em referência à autorealização ética, à liberdade pessoal de ação, à autolegislação política ou à autodeterminação moral. Em tais contextos novamente a própria constituição do self (em que a pessoa ética é considerada membro de uma comunidade constitutiva da identidade) pode se distinguir da pessoa de direito (membro de uma comunidade de direito), bem como o cidadão (que pertence à comunidade política) desempenha um papel diferente daquele da pessoa moral (pertencente à comunidade moral de agentes moralmente autônomos). Liberais e comunitaristas não compreenderam justamente que nenhuma dessas concepções de autonomia pode pretender ser a única válida como base da justiça. Por essa razão, a tarefa da análise crítica é saber como integrá-las, compatibilizá-las e perceber quando entram em conflito "de modo que uma dimensão não seja sacrificada em nome das outras" (p.306).

O livro não se limita à analise crítica dos argumentos normativos sobre a justiça. Há também um importante balanço sobre os princípios de legitimação do poder político em sociedades complexas e pluralistas. Forst amplia o quadro de discussão analisando princípios de justificação pública ao debater com as correntes deliberativas da democracia, com a crítica feminista do liberalismo, dilemas multiculturais e com a literatura sobre a sociedade civil. Sua intenção é pensar criticamente os pressupostos socioculturais das sociedades democráticas, ou seja, entender como os cidadãos se compreendem como membros de uma comunidade política e sob quais condições justifi- 
cam publicamente normas que retiram sua legitimidade de discursos democráticos. A crítica de Forst implica pensar a relação entre cidadania e justiça social a partir de um ethos democrático constitutivo das práticas de justificação da normatividade sem cair, contudo, na oposição liberal/comunitarista. Mesmo que os próprios cidadãos precisem se compreender como participantes e responsáveis na regulação e na ação políticas, não são os valores éticos compartilhados que orientam legitimamente suas pretensões por reconhecimento e realização de direitos. Orientam-se antes pelo ideal de cidadania ativa, de modo que o ethos da democracia não consiste senão na realização das dimensões da própria autonomia do cidadão.

Forst mantém, assim, uma atitude crítica diante das teorias normativas existentes. $\mathrm{Na}$ verdade, Contextos da justiça não pretende ir além dessa análise exaustiva das justificações normativas contidas nos discursos teóricos que compõem o amplo debate entre liberais e comunitaristas, ficando para seu outro livro a tarefa de compatibilizar uma reconstrução teórica com a dimensão histórica, como no caso, por exemplo, dos fenômenos da tolerância ${ }^{15}$. De todo modo, não há teoria crítica sem que se enfrente as teorias capazes de representar da melhor maneira os problemas de nossa época. Assim como fez Marx em seu tempo ao empreender uma "crítica da economia política", a tarefa atual implica necessariamente uma crítica das mais importantes correntes teóricas vigentes - embora não mais da economia política, mas sim da filosofia política contemporânea com sua pauta de problemas e desafios ligados à moral, ao direito e à democracia. ${ }^{16} \mathrm{E}$ para tanto, a análise crítica não oferece uma "nova" teoria da justiça, apenas acusa a parcialidade das oposições vigentes, reconstruindo seu sentido. Nessa relação com a filosofia política, a teoria crítica também não precisa abrir mão dos fundamentos normativos em que se apoiam tais teorias, bastando justificá-los de forma mais adequada em face dos complexos contextos da justiça.

RÚRION MElo é professor de Teoria Política do Departamento de Ciências Sociais da Unifespe pesquisador do Núcleo Direito e Democracia do Cebrap.
[15] Cf. Forst, R. Toleranz im Konflikt, op.cit.

[16] Cf.o programa de pesquisa apresentado em Forst e Günther, op. cit. 
ESTE NÚMERO FOI FINANCIADO PELA FUNDAÇÃo CARLOS CHAGAS 